FROM THE ARCHIVES

Ed. Alois Pichler

\author{
Joachim Schulte \\ Joachim.Schulte(at)access.uzh.ch
}

\title{
Text-Genetic-Philosophical Notes About the Wittgenstein Nachlass: Band Series I Items MSS 105-122
}

\section{Abstract}

The Wittgenstein Archives at the University of Bergen (WAB) has commissioned Joachim Schulte to author text-genetic-philosophical descriptions for each single item of the Wittgenstein Nachlass. The descriptions, called "notes", will be published successively in the metadata section (" $m$ ") of the Bergen Nachlass Edition (BNE) on Wittgenstein Source http://www.wittgensteinsource.org/ (for an example see http://www.wittgensteinsource.org/Ms-105 m). Moreover, the descriptions will, beginning with this issue, be published in packets in the "From the Archives" section of the Nordic Wittgenstein Review. This first publication includes descriptions of each item pertaining to the first Band series of the Nachlass, numbered by Wittgenstein I-XVIII (MSS 105-122), as well as a description of the entire series as such. 


\section{General note on MSS 105-122 (Bände I to XVIII)}

Between 1929 and 1940 Wittgenstein produced 18 large manuscript volumes. He himself numbered them as Bände I to XVIII and gave most of them general titles like "Philosophical Remarks" or "Philosophical Grammar". This indicates that he himself perceived these volumes as belonging to a series. Some of them evidently contain new material spontaneously written down and not drafted in other notebooks. Parts of several of these volumes, however, are based on earlier remarks recorded in pocket notebooks, for example, while other parts contain revisions of earlier manuscript volumes or typescripts. The best-known case of this last kind are MSS 114ii and $115 \mathrm{i}$ (Bände X and XI), which contain a revision (erste Umarbeitung) of parts of TS 213 (The Big Typescript). The same typescript forms the basis of the first section of volume XII (MS 116), but the process of selecting remarks from the TS and transferring them into Band XII is such that most people would not feel inclined to speak of a process of revision. At any rate, there are clear breaks between the earlier portion of MS 114 and the subsequent revision of TS 213 contained in the same ledger as well as between the first half (winter 1933-34) of volume XI and its second half, which was written in the late summer and the autumn of 1936 (containing the German revision of the Brown Book, entitled "Philosophische Untersuchungen").

\section{General note on MSS 105-114 (Bände I to X)}

There are good reasons for treating the series of volumes from I to $\mathrm{X}$ (or, more exactly, up to MS 114 $4_{\mathrm{i}}$ ) as forming a separate, or separable, part of Wittgenstein's oemure. However, as has been pointed out above, even these volumes were not produced according to one uniform pattern. Some of the remarks were written spontaneously, as it were, that is to say, without a basis in earlier drafts. Other remarks contained in these volumes were copied or transferred in revised form from earlier writings. Most of these volumes are punctuated by personal remarks of a private or confessional nature as well as by reflections on music, literature, religion, and a few other kinds of topic. Sometimes, but by no means always, these reflections are separated from the more 
straightforwardly philosophical material by certain marks (e.g. " ||$\ldots|| ")$ or by being written in Wittgenstein's usual code. But in spite of these and other qualifications that might come to mind it is helpful and surely not misleading to view volumes $\mathrm{I}$ to $\mathrm{X}$ as the central record of Wittgenstein's strikingly original and continuous production between his return to Cambridge in January 1929 and a new stage in the process of articulating and arranging his ideas. But even if we are agreed that these ten manuscript volumes are to be regarded as the core record of his thought during the early middle period of his philosophical development, it will be useful to divide this material into three parts, corresponding to interruptions of the writing process motivated by an urge to have his handwritten remarks typed up. Once in possession of a typed version, Wittgenstein was prepared to think about the order of his individual remarks, about possible arrangements and re-arrangements. Moreover, he could now proceed to actually carrying out such arrangements and re-arrangements by way of cutting typescript or carbon copy into fragments that were subsequently put together in a new order and, in some cases, supplemented by handwritten changes or explanations or exemplifications giving the older material a new twist. - There are three interruptions of the kind alluded to in the previous paragraph:

(1) 24 March 1930: Easter vacation, in Vienna Wittgenstein dictates selected remarks from vol.s I to IV. The result is TS 208, which is soon cut into fragments that are subsequently re-arranged so as to form TS 209 (Philosophical Remarks).

(2) The material written down in the remainder of volume IV (MS 108) between 25 April and 9 August 1930 is dictated and typed sometime in the summer of this year (TS 210).

(3) The contents of MSS 109-114 $4_{i}$ are sifted and dictated to a typist while on vacation in Austria. The resulting typescript (TS 211) comprises ca. 800 pages and may have 
been dictated in the course of two or more series of sessions. But most of the work of producing this typescript was surely done after 5 June 1932 (the last date to be found in MS 114i).

It is likely that TS 211 was completed in the summer or autumn of 1932. So we may assume that in the course of less than four years (1929-32) Wittgenstein managed to fill ca. 3000 pages of manuscript volumes and dictated almost 1100 pages of this material to a typist. The story of this material is continued in other parts of this account (see especially MSS 114-15, 140, TSS 208-13), but at this point, readers should allow the message to sink in: if we remember that much of this material was absolutely new and the result of reflections that stood in contrast, or were diametrically opposed, to the author's earlier convictions, we find that we are dealing with a unique document witnessing to Wittgenstein's stunning creative powers.

\section{General note on MSS 116-122 (Bände XIII to XVIII)}

Chronologically speaking, the first two (of four) parts of $116\left(=116_{\mathrm{i}}\right.$ and $\left.116_{\text {ii }}\right)$, the first part of MS $117\left(=117_{\mathrm{i}}\right)$, the whole of MS 118, and most of MSS 119 and 120 are very closely connected, even interrelated; at some points one might speak of overlap. Many entries bear a date or are easy to date.

The connections between the relevant parts of MSS 117-120 can, very roughly speaking, be described as follows: MSS $117_{\mathrm{i}}-120_{\mathrm{i}}$ are Wittgenstein's notebooks from the time he spent in Norway after his return there in August 1937. The earliest entries can be found in MS 118 (continuously dated from 13.8. to 24.9.37). Similar observations apply to MS 119, which is the immediate continuation of MS 118 (beginning on 24.9., running on to 19.11.), and virtually all of MS $120_{\mathrm{i}}$ (beginning on 19.10. and running on to 10.12. — the day before Wittgenstein's departure from Skjolden).

MSS 118 and 119 resemble each other in several respects: both of them are used by Wittgenstein as notebooks from which he picks certain remarks which are then transferred and revised in MS 117; both of them contain a fair number of diary remarks chronicling the history of Wittgenstein's contemporary writings as well as of his 
moods, impressions, and feelings. MS $117_{i}$, on the other hand, is basically a reservoir of more or less polished remarks selected from MS 118 and, to a small extent, from MS 119, and in contrast to these latter two does not contain a journal.

Owing to the existence of this journal, we are informed about an interruption in Wittgenstein's work, which can be dated as having occurred more or less exactly on 23 October 1937. The interruption is due to his having taken out his "old typescript" (as he calls it now), that is to say, a copy of the Big Typescript (= TS 213). From this point onwards, he re-reads large parts from the first half of this typescript and works on it in the following sense: he selects remarks that arouse his interest and copies them in more or less revised form into a very large and so far unused manuscript book. This is MS 116, which, as it were, contains the result of Wittgenstein's temporary loss of interest in the work he was doing in MSS 117-119.

One of the most striking features of volumes XIV to XVI is the journal Wittgenstein keeps in these manuscript volumes. Many, but by no means all, of the remarks forming this journal were written in code. This habit of regular journal-writing was interrupted around the time Wittgenstein spent in Dublin in February and March 1938. This was the time of the Anschluss and increased worries about the safety of his relatives. These worries and the difficulty, or impossibility, of concentrating on his own problems and writings may have been a crucial factor contributing to Wittgenstein's giving up on his journal.

Of course, this is not the only difference between volumes XIII to XVI, on the one hand, and the last two (XVII and XVIII), on the other, but it is a convenient way of marking a break. At the same time, we must remember that volume XIII (= MS 117) itself forms a composite structure made up of heterogeneous parts: its first part is closely connected with MSS 118 and sections of 119, but other parts of MS 117 are in no way connected with this conglomerate, while its last part (= MS 117 ) even brings up the rear inasmuch as it constitutes the continuation and terminus of the train of remarks making up MS 122. This latter manuscript volume is the last one of those Bände Wittgenstein marked as belonging to a special series by assigning Roman numbers to them. Perhaps there is a certain irony 
in the fact that the tail end of the series is not to be found in the as it were "officially" last volume but was tucked away in an earlier one.

\section{MS 105}

\section{Philosophische Bemerkungen}

One peculiar feature of MS 105 is this: its first two verso pages are used as a kind of journal and record some of Wittgenstein's impressions and feelings during the first days after his return to Cambridge (dated 2, 4, 7, and 15 February 1929). The recto pages were evidently destined to be used for more straightforwardly "philosophical" entries (dated 2, 4, 5, and 6 February). There are no further dates to be found in this or the next volume (MS 106). The next date to be found after this long gap is 11 September 1929 (p. 87 of MS 107), and the regular dating of manuscript entries begins " 6 October" (p. 153 of MS 107, that is to say: there is a completely undated part of these manuscript volumes comprising more than 500 pages between February and September 1929).

Another peculiarity of this manuscript volume is the following: once he has reached the end of the recto pages in MS 105, Wittgenstein continues his remarks in the next volume (MS 106), following the same method as in MS 105, that is, filling first all the recto and then all the verso pages (if one allows for the exception of a few journal entries on p. 4). Only after having filled the whole of volume II does Wittgenstein return to volume I (MS 105) to write on the pages left blank during the first round of recording his ideas.

In MSS 105-8, Wittgenstein uses the marginal signs "/" and "*” for the purpose of selecting remarks. Practically all the remarks marked by an "/" were transferred into TS 208, whereas hardly any of the remarks marked by an "*" found their way into the typescript.

As regards the contents of these remarks, there are passages and wordings strikingly reminiscent of the Tractatus next to observations obviously critical of or very remote from the spirit of Wittgenstein's book. Topics discussed are: visual space, questions in number theory, the ideas of object and complex, concepts like "axiom" and "picturing" or "projection". The names of Frege, Russell, and Ramsey are mentioned several times. Some of these topics and 
names return in the second part of this volume (that is, after the discussions in MS 106), and in addition, there is interesting material on the idea of verification and the notion of a system.

On the whole, one may want to say that while the first pages of these notes tend to sound tentative and, perhaps, a little diffident, it does not take Wittgenstein very long to gather his wits and to write with a degree of confidence that may seem surprising in one who has only recently resumed thinking and writing about these questions after ten years' absence from the scene.

Much of this material can be found in Philosophical Remarks.

\section{MS 106}

II.

As has been pointed out under the heading "MS 105", MS 106 is the immediate continuation of the first half of MS 105 and is, in its turn, continued by the second half of MS 105 (Band I). Volume II is the only one among the first ten manuscript volumes which bears no title. In view of the fact that it is engulfed, as it were, by the two parts of volume I, one may feel inclined to use the title of MS 105 (Philosophische Bemerkungen) for MS 106 as well.

The first pages in MS 106 are continuous. On p. 4 there are a few journal entries (written in code) where Wittgenstein wonders whether he is the right person for the work he intends to do and observes that he finds it relieving to write down in code those observations that he does not wish to set down in readable form. On p. 149/296 of the manuscript volume Wittgenstein notes "Fortsetzung auf den Verso-Seiten vorne!", thus advising the reader to return to the beginning of the manuscript volume, where, on p. 6, he will find the note "Anschluß an die letzte Rectoseite!", thus pointing out where the reader can find the continuation of what he has been studying so far. Only after the reader has gone through ca. 150 verso pages (ending in 295, 297, $298=150$ ) is he supposed to return to MS 105, where he will (on p. $6=133$ ) find the note "Fortsetzung der philosophischen Betrachtungen des II. Bandes", 
indicating that the next ca. 65 verso pages continue the text of volume II.

Like the recto pages of 105 , much that is written on the early pages of MS 106 will strike most readers as rather tentative. After another 100 or 200 pages, the author sounds much more confident. Questions discussed include generality, time, syntax, colours, intuitionism, infinity, internal relations, and various other ideas. There are illustrations and remarks strongly reminiscent of Wittgenstein's paper "Some Remarks on Logical Form". He does, for example, mention the idea of representing the distribution of colour patches by reference to a system of coordinates as well as ways of projecting geometrical figures from one plane onto another plane.

Besides the names of authors alluded to in MS 105, there are references to Nicod, Brouwer, and Weyl, for example.

Many of the remarks contained in this manuscript volume can be found in Philosophical Remarks.

\section{MS 107}

\section{Philosophische Betrachtungen}

MS 107 (Band III) forms the immediate continuation of MS 105 (verso pages of vol. I). The page numbering is straightforward from 1 to 300. There is an interruption, however, on p. 229 (4 December 1929), and this interruption coincides with Wittgenstein's Christmas vacation (spent in Vienna). Evidently, when departing for Austria he left his current manuscript volume in Cambridge. Once in Vienna, he began to use a new manuscript volume (MS 108, vol. IV). After his return to Cambridge, however, he went back to the earlier volume (MS 107) and filled its last 70 pages between 10 January (p. 229) and 15 February (p. 300). So, if one wishes to read Wittgenstein's manuscript remarks in their chronological order, one should, upon reaching p. 229 of Band III, turn to Band IV to peruse the first 64 pages of this manuscript volume (13 December 1929 to 5 January 1930). 
The first date to be found in MS 107 is "11 September" (p. 87). Regular dating begins on p. 153 (6 October 1929).

This volume contains a great number of general and personal reflections; a surprising proportion of these is not contained in Georg Henrik von Wright's collection Culture and Value. Among these general or personal remarks, there is a long sequence of reflections on the point of keeping a journal (pp. 74-6), and there are characteristic observations on what would constitute Wittgenstein's ideal, or cultural ideal, as well as equally characteristic comparisons with Mendelssohn. - There is an extended dream narrative on pp. 219-22 (1 December 1929).

Philosophically, many of the remarks in this volume deal with Wittgenstein's chief concerns typical of this period of his life: the possibility of a phenomenological language, visual space, questions arising in the areas of number theory and arithmetic, generality, the roles played by various types of rule and the ongoing conflict between extensional and intensional approaches to our notion of the infinite. The analogy between distinct "spaces" of experience and the contrast between a screen picture, on the one hand, and the corresponding picture(s) on a strip of film, on the other, is developed. Other topics are verification, Galton's photographs, potential uses of the subject-predicate form, sense-data and sensations (pain), hypotheses, expectation.

Authors referred to include (besides Frege, Russell, Ramsey) Einstein as well as Ogden and Richards.

Much of this material can be found in Philosophical Remarks, and a fair number of the remarks contained in this manuscript volume were published in Culture and Value.

\section{MS 108}

\section{Philosophische Bemerkungen}

As was pointed out in the description of MS 107 (Band III), the first 64 pages of the present manuscript volume (MS 108, Band IV) were written at the time of Wittgenstein's Christmas (1929) vacation in Vienna. The remarks composed during this period were continued on the last 70 pages of Band III. Now the second part of MS 108 
forms the immediate continuation of this material in MS 107. It begins at the bottom of p. 64; the first remark is dated 16 February 1930. In the beginning, the dating is pretty regular, but dates (and entries) become much sparser as the Lent Term (the first term of Wittgenstein's lectures) progresses. In the middle of March he travels to Vienna. Here, he continues to write a few remarks (the last date is 24 March 1930, p. 118), but most of his time was taken up by dictating the text of TS 208, which later came to form the basis for TS 209 (Philosophische Bemerkungen). On 25 April, after his return to Cambridge, he resumes work on MS 108. (The first remark, however, dated "25.4.", is a journal entry which refers back to his life in Vienna, which he has just left.) The concluding 165 pages or so of MS 108 were written between 25 April and 9 August 1930. Sometime after the end of the Easter Term, Wittgenstein travels to Austria, where he continues to fill this manuscript volume and finally decides to dictate it all to a typist. So, the second half of Band IV (pp. 133300) forms the basis for TS 210 , which was no doubt produced in Austria during the summer of 1930.

Most of the philosophical topics dealt with in this manuscript volume are the same as those mentioned in our description of previous volumes. The first part of MS 108 contains an interesting account of solipsism and the idea (also mentioned in Waismann's records of conversations with members of the Vienna Circle) of a centre of language which can only show itself through the use of language. In later remarks of our volume, Wittgenstein discusses our notions of analysis, grammar, axiom, etc., and he tries to get clearer about the contrast between primary and secondary language. Further central ideas are those of Übersichtlichkeit (surveyability) and memory as a source of time. At one point (p. 277) he makes the characteristic observation that "language is the only means of explaining language, and this is why there is no way of explaining language".

Much of the material contained in the first half of this manuscript volume was published in Philosophical Remarks, and a fair number of remarks contained in the second half found their way into the Big Typescript while other ones ended up in Zettel. 


\section{MS 109}

\section{Bemerkungen}

While the last remarks of MS 108 are dated 9 August 1930, the first entry of MS 109 (= Band V) was written on 11 August 1930. At this time, Wittgenstein was living in the game keeper's cottage of the family estate Hochreit (cf. note by Brian McGuinness in Wittgenstein in Cambridge, p. 189). The first 160 pages of this manuscript volume are filled with daily entries spanning the time between 11 August and 19 September 1930. At this point there is an interruption which seems to coincide with Desmond Lee's visit to the Hochreit estate (see letter to G.E. Moore [August 1930]). Work on this manuscript volume was only resumed after Wittgenstein's return to Cambridge: his first observation, noted on 7 October, reads: "Es gibt keine Metamathematik" ("There is no such thing as metamathematics"). In the sequel there are scattered remarks up to 22 October. From this day onwards, Wittgenstein continues his work in the shape of another uninterrupted series of remarks reaching up to 2 December 1930 (p. 271 of MS 109). At this point, Wittgenstein was leaving Cambridge to spend the Christmas vacation in Vienna, where he began a new manuscript book (MS 110) on 10 December. Some time after his return to Cambridge, on 29 January 1931, he went back to MS 109 to fill its last 30 pages between 29 January and 3 February 1931.

So, if a reader wishes to study Wittgenstein's remarks in their chronological order, he will have to move from p. 271 of Band $\mathrm{V}$ to the first pages of Band VI (covering the period between 10 December 1930 and 28 January 1931) before returning to Band V (p. 272, 29. 1. 31). The last remark contained in MS 109 (= Band V) ends in midsentence and is continued on p. 31 of MS 110 (= Band VI, 3 February 1931).

Thus, most of the material contained in Band $\mathrm{V}$ represents the results of two uninterrupted periods of work. The first of these two periods continues the series of remarks begun in summer 1930 up to an interruption of seven weeks between 19 September and 7 October 1930. The second period coincides with Wittgenstein's stay in Cambridge during Michaelmas Term 1930. 
Most of the topics discussed in MS 109 are known from publications like Philosophical Grammar and Wittgenstein and the Vienna Circle (one of the conversations recorded in this latter book took place on 25 September 1930). To mention just a few of these topics: grammar and grammatical rule, generality, and Wittgenstein's technical notion of a hypothesis. There are a number of memorable observations on the practice of philosophy (e.g. the claim that the method of philosophy consists in curing one's self-induced madness [p. 84, 2. 9. 30]) as well as striking remarks on the nature and the limits of language. There is a good deal on the notion of a Satz (sentence, proposition) and on drawing distinctions between sense and nonsense and between symptoms and criteria. Wittgenstein continues to discuss the concept of intention as well as problems concerning the idea of possible fulfilments of expectation. The Fregean notion of Annahme plays a certain role, and Wittgenstein keeps coming back to questions regarding our concepts of negation, logical multiplicity, analysis, belief, and the meaning of proper names ("Nothung").

Various interesting remarks known from the collection Culture and Value were jotted down in Band V, for example the well-known "Sketch for a Foreword". Names mentioned include, besides those of Frege and Russell, Bergson, Paul Ernst, Freud, Meinong, and Renan.

Many but by no means all the remarks contained in this manuscript volume were transferred to TS 211.

\section{MS 110}

\section{Philosophische Bemerkungen}

As was pointed out in our description of MS 109, the chronological order of remarks in MS 110 is interrupted (on p. 31) and requires readers keen on chronology to go back to Band $\mathrm{V}$, whose last thirty pages constitute the continuation of the sequence of remarks running from p. 1 of Band VI (10 December 1930) to p. 31 (28 January 1931). The last remark of MS 109 is continued and concluded in MS 110 (p. 31, 3 February). This series of remarks runs 
on practically without interruption for more than one hundred pages (almost daily entries up to $13 \mathrm{March}$ ). Then there is one further short set of remarks dated 17 March, which is followed by a "Nachtrag [addendum] 3. 5", thus signalling a gap of five weeks. It is likely that Wittgenstein spent some of the time between 17 March and the beginning of May working on other manuscripts (pocket notebooks, perhaps, or loose sheets). This would go some way towards explaining some of the entries marked as Nachträge in the remainder of MS 110 (e.g. pp. 185 [21(?) June 1931]; 202, 22 June; 212, 24 June). On p. 177 (19 June 1931), readers will find the beginning of remarks on Frazer's Golden Bough and related matters well-known through various publications of this material (see e.g. Philosophical Occasions, pp. 115-155). Another notable feature of this manuscript volume is the fact that from p. 223 (25 June), most remarks are taken (in more or less revised form) from MS 153a (see there) - the first (and only) date in this pocket notebook is 10 May 1931 (p. 4v). The last remark in MS 110 taken in this way from MS 153a (p. 59r) can be found on p. 300 (6 July 1931). This use of pocket notebooks is continued in the following Bände VII to IX (partly based on pocket notebooks 153a, b, 154, and 155).

The first entries of MS 110 date from December 1930, when Wittgenstein was staying with his family in Vienna. These Christmas vacations were punctuated by a remarkable number of conversations with members of the Vienna Circle (Wittgenstein and the Vienna Circle, 17, 26, 28, and 30 December 1930; 1 and 4 January 1931). He returned to Cambridge before 12 January and stayed there until 15 March (see description above, where it was observed that the uninterrupted sequence of remarks comes to an end around 13 March). He left Vienna for Cambridge on 17 April, returning on 8 June to Vienna, where he had regular meetings with Schlick.

Most of the topics discussed in this manuscript volume are familiar to readers of Philosophical Grammar and Wittgenstein and the Vienna Circle. There is little on the philosophy of mathematics but a lot on the nature and limits of language. There are a few remarks underlining Wittgenstein's anti-dogmatic attitude. As was said above, there is a longish section containing observations on Frazer and related matters. In addition, there are tentative discussions of privacy and remarks on the notions of intention and convention, on the idea 
of separate or separable spaces (as in "visual space"), and on symbols and their sense. A certain prominence is given to the idea of thought as a process and the confusing effects of this idea. A good deal of space is devoted to questions of meaning, to problems arising from claiming to understand a given Satr, and to the nature of philosophy. There are echoes of Wittgenstein's early thought in his remarks on the context principle and the variety of uses one can make of the concept of a picture. What seems particularly characteristic of Wittgenstein's work of this period are his numerous observations on rules of various kinds, in particular grammatical rules, as well as on grammar and grammatical systems more generally conceived.

Again, there is a fair number of remarks known from the collection Culture and Value. Among the names mentioned in this manuscript volume there are those of Augustine, Bergson, Cantor, Matthias Claudius, Paul Ernst, Frege, Goethe, Kant, Lessing, Ogden \& Richards, Russell, Schiller, and Spengler.

A great number of remarks were marked by a slash ("/") and duly transferred to TS 211.

\section{MS 111}

\section{Bemerkungen zur Philosophie}

The last entry of Band VI is dated 6 July 1931, and the first entry of Band VII bears the date 7 July. As regards the remainder of this manuscript volume, dating is not as regular as in some other notebooks (the last date - 13 September 1931 — can be found on p. 167 of 200 pages in all). This fact is no doubt connected with Wittgenstein's working technique: just as in the last part of MS 110 and in subsequent MSS $112-114_{\mathrm{i}}$, he chiefly relies on previously written material - either on pocket-notebook entries probably pencilled only a short time before being transferred to Bände or on remarks collected in TS 208. As regards MS 111, the pocket notebooks concerned and used alternatingly are MSS 153a and 155.

In MS 111 (pp. 28-31), we find the first of several passages in Wittgenstein's MSS 111-114 i $_{i}$ where he draws on earlier material selected and collected in TS 208. Here, he goes back to these records 
of earlier reflections and resumes his discussion of questions arising in that context: this is why Wolfgang Kienzler, in his account of Wittgenstein's "turnaround", speaks of various stages of a Wiederaufnahme (resumption) of this TS 208 material (see Kienzler, Wittgensteins Wende zu seiner Spätphilosophie [Frankfurt/M. 1997], ch. 2; cf. early suggestions in: Alois Pichler, Untersuchungen zu Wittgensteins Nachlaß [Bergen 1994], ch. 2.4 [pp. 77-80]).

The impression that in reading this volume and other ones from this period we are dealing with records of ideas in transition is borne out by the fact that we find remarks like "To understand the meaning of a word amounts to knowing, understanding, its use" (p. 12) almost immediately followed by an observation like "Thus an elementary proposition is such that in the calculus I am employing now it does not figure as a truth-function of other propositions" (p. 13). That is to say, remarks foreshadowing characteristic features of Wittgenstein's later thought rub shoulders with much earlier ideas or backward-looking material.

Practically all the topics discussed in this volume are familiar to readers of Philosophical Grammar or Wittgenstein and the Vienna Circle. There are many remarks on grammar and rules, and Wittgenstein expounds his simile of celluloid vs. screen pictures (cf. Wittgenstein and the Vienna Circle, p. 50 \& passim, and my description of MS 107). He emphasizes his anti-dogmatism and deals with various questions in the philosophy of mathematics such as recursion, proof, intuitionism, and the idea of a calculus (concerning which he wonders whether one could claim that it is not a mathematical notion at all, p. 74).

Two among several striking features of this manuscript volume are, first, a number of allusions to Augustine's account of a child's learning his first language (which is of course well-known from $\$ 1$ of PI). The second one is the frequency of observations on Plato and Socratic dialogues in general. These observations can give us an idea of Wittgenstein's interest in Plato's thought and of what aspects of this thought he found worth discussing (see Wolfgang Kienzler's contribution to Perissinotto \& Cámara [eds.], Wittgenstein and Plato [Houndmills, 2013, pp. 25-47]).

Again, there is a fair number of remarks known from the collection Culture and V alue. Authors mentioned (besides Augustine, 
Plato, and Socrates) include C.D. Broad, Frege, Goethe, W.E. Johnson, Kleist, Mendelssohn, Ramsey, Skolem, Spengler, and Weininger. The last five pages of this manuscript volume are devoted to a discussion of a play on Orpheus drafted by Paul Engelmann (for the text of this work see Wittgenstein-Jahrbuch 2001/2002, pp. 297341, and the account given by Josef Rothhaupt, ibid., pp. 343-367).

A great number of remarks were transferred to TS 211, quite independently of whether or not they were marked by a slash (“/”).

\section{MS 112}

\section{Bemerkungen zur philosophischen Grammatik}

The 270 pages of this manuscript volume cover the period between 5 October and 28 November 1931. As in MSS 111 and 113, Wittgenstein relies heavily on material written earlier, partly on pocket notebooks 153a, 153b, and 155, partly on remarks collected in TS 208 (pp. 2-17), here used towards the end of Band VIII.

The questions discussed in this manuscript volume cover a wide range of philosophical problems. There is a good deal on the philosophy of mathematics, e.g. number-theoretical considerations as well as discussions of central concepts (like those of proof and infinity) and methods of proof (like mathematical induction and construction). Some basic concepts examined have a bearing both on the philosophy of mathematics and the philosophy of language, as for example the central notion of Spiel (game or play). A great number of Wittgenstein's remarks centre around questions concerning possible links between language and world. So there are observations on ostension, in particular a long discussion of the notion of a Muster (sample or paradigm) and the relations between Muster and words. Other familiar topics include the question whether bearerless proper names can be said to have meaning ("Moses") and what the contribution of techniques of verification to linguistic meaning could be seen to consist in. Attempts are made to distinguish between explanation and description, and there are a number of remarks on colour and visual space. It almost goes without saying that there are general observations on the practice 
and point of philosophy and the confusions engendered by metaphysical ways of asking questions.

There are more than a dozen remarks that appear in the collection Culture and Value. Names mentioned include Cantor, Eddington, Frege, Hilbert, Lichtenberg, Ramsey, Russell, Sheffer, Skolem, Tolstoy, and Whitehead.

Most but by no means all the remarks contained in this volume were transferred to TS 211.

\section{MS 113}

\section{Philosophische Grammatik}

Like the next volume (no. X), this manuscript book bears the title "Philosophical Grammar". The first sentence on p. 1 continues the last sentence begun (and left hanging) on the last page (136r) of the previous volume (MS 112, vol. VIII, 28 November 1931). The first new remark, following the continuation of the last remark begun in volume VIII, bears the date 29 [November 1931]. The dating continues $1.12 .31,3.12 .31$, but then there is a long interruption coinciding with the Christmas vacation. Dates resume with 16.2.32 (p. 18v), 17.2.32, etc., but soon there is another gap between 8 March and 18 April 1932 (p. 51v), coinciding with the Easter vacation. After this, the dating is very regular and runs up to 28 May 1932 (p. 144r).

Parts of this manuscript volume are based on preceding work done in pocket notebooks $153 \mathrm{~b}$ and 154 as well as on earlier material collected in TS 208 (in Kienzler's terminology, this is the 3rd "resumption", covering pp. 19-90 of TS 208, cf. my description of MS 111, above). The entire volume contains virtually no marginal marks indicating Wittgenstein's judgement and his decision on what to do with individual remarks. Perhaps he felt that no such marks were needed, as almost 100 per cent of the material was transferred to TS 211 and later to TS 213.

There is a good deal on questions concerning the foundations of arithmetic and the idea of generality. The notion of a rule (of grammar, of a game) and, in particular, the idea of the arbitrariness 
of rules are extensively discussed, and there are occasional remarks on the relation between rules and empirical sentences. There are numerous references to Russell, Frege, and Ramsey; Augustine, Brouwer, Driesch, and Sraffa are also mentioned. The importance of the notions of Übersicht and Übersichtlichkeit (surveyability) is emphasized. The concept of verification plays a great role, and there is a sustained discussion of pain, especially toothache. As in most other manuscripts from this period, there is a number of observations and asides on philosophy in general. It seems that on pp. 45r (1 March 1932), 50r-51r (8 and 10 March) we encounter the earliest uses of the word "Sprachspiep" ("language-game"), cf. MS $154: 52 \mathrm{v}$. Moreover, there are discussions of mathematico-logical concepts (such as infinity vs. endlessness or continuity, the ancestral, and provability) and of our notion of a visual field and the relevant meaning of words like "hazy" \& "blurred".

Many sections of MS 113 are known to readers of the book Philosophical Grammar, especially of its second part. Moreover, a few remarks can also be found in Philosophical Remarks. MS 113 contains only one remark that was included in the collection Culture and $V$ alue.

\section{MS 114}

\section{Philosophische Grammatik (= MS 114i, fol. 1-31 [= pp. 1-60])}

\section{Umarbeitung (=MS 114ii, pp. 1-228)}

Like the previous volume (no. IX), this manuscript book bears the title "Philosophical Grammar". For obvious reasons, however, this title only applies to the first 60 pages of this volume. The foliation (beginning on the title page) was added later (but not by Wittgenstein himself).

On the flyleaf Wittgenstein wrote a note (mostly in code) to the effect that, if he died before completing his work, this material should be published as a fragment under the title "Philosophical Remarks", and the publication should be dedicated to Francis Skinner, who was to be notified of this fact: 
Im Falle meines Todes vor der Fertigstellung oder Veröffentlichung dieses Buches sollen meine Aufzeichnungen fragmentarisch veröffentlicht werden unter dem Titel:

"Philosophische Bemerkungen"

und mit der Widmung:

\section{"FRANCIS SKINNER zugeeignet"}

Er ist, wenn diese Bemerkung nach meinem Tode gelesen wird, von meiner Absicht in Kenntnis zu setzen, an die Adresse: Trinity College Cambridge.

The first 60 pages of volume X (often referred to as MS 114, i.e. the first section of MS 114) constitute the last part of the manuscript material Wittgenstein used to compose TS 211, which in its turn served as the basis of the collection of remarks TS 212 and the subsequent dictation of TS 213, the so-called "Big Typescript". A fair number of remarks in MS $114_{i}$ are revised versions of earlier remarks, chiefly taken from MSS 107 and 108 via TS 208. The last couple of pages or so were used to form the beginning of TS 219 (possibly, these last pages were written a little later than the first 58 pages).

These first 60 pages of the manuscript volume bear frequent dates, beginning from 27.5 .32 (p.1), 30.[5.] (p. 12), 1.6. (p. 22), 3.[6.] (p. 32), 4.[6.] (p.41), 5.[6.] (p. 44)

On p. 40 there are three remarks (chiefly on probability) cut from TS 208 and glued in at this point of vol. X.

The second and much larger section of MS 114 (=114 ii) was paginated by Wittgenstein himself (228 pages). Its title is Umarbeitung (Revision), and, as a kind of second title, Wittgenstein added the words Zweite Umarbeitung im großen Format (Second revision in LargeSize manuscript). This refers to the first 39 pages of MS 140 (p. 40 contains an early draft of what we know as the beginning of Philosophical Investigations). The title Umarbeitung as well as the explanation concerning the second revision were obviously added at a later stage: they were squeezed into the space above the first proper line of the first remark of this (first) revision. 
This revision is mainly one of TS 213, the Big Typescript, which, immediately after its completion in the summer of 1933, was supplemented and corrected in Wittgenstein's own handwriting. At a certain point, the space afforded by the pages of the typescript must have seemed insufficient to allow the author to annotate and reorganize his material. So he used the free pages of his last large manuscript volume (114) to copy the revised versions of those remarks from TS 213 that he intended to keep. When, at some later stage, he decided to change the order and part of the content of the material assembled in MS 114 $4_{\mathrm{ii}}$, he used the loose leaves of MS 140 (Großes Format) to do so. Thus, the reader who wishes to follow Wittgenstein's instructions about how to read, or "construct", this second revision will have to switch back and forth between the manuscript volume (MS 114 ii) and the loose leaves constituting the Großes Format (MS 140). Of course, keeping a copy of the Big Typescript handy will also contribute to understanding the piecemeal composition of the text.

Moreover, in the later stages of rewriting the remarks based on the Big Typescript, Wittgenstein drew not only on the typescript itself as well as his revisions in the margins and on the versos of its pages but also on a smaller manuscript book (MS 145, aka "C1"). On the last page (228) he inserted a remark from MS 146 ("C2"), which is continued on the first page of MS 115 (see there). As the first page of MS 115 bears the date "14.12.33", we can infer that the material contained in MS $114_{\text {ii }}$ was written in the weeks or months between his first attempts at revising TS 213 and the middle of December 1933.

The contents of MS 114 $4_{\mathrm{ii}}$ (plus MS 140) are known to readers of the first half of the book Philosophical Grammar (ed. by Rush Rhees). 


\section{MS 115}

\section{Philosophische Bemerkungen}

Fortsetzung von Band $X$. (= MS 115i, pp. 1-117)

\section{Philosophische Untersuchungen. Versuch einer Umarbeitung (= MS 115 ii, pp. 118-292)}

This manuscript book bears the title "Philosophical Remarks", but on account of the fact that its second part (the German translation and revision of the Brown Book) should be regarded as a separate (part of the) manuscript, this title may be seen as only applying to the first 117 pages of this volume. The pagination is Wittgenstein's own throughout.

On the inside of the cover of this manuscript book Wittgenstein wrote a note (in code) to the effect that, even though it may well be possible to shorten this book, it would be extremely difficult to do so properly. To this, he added the rider that his observation does not apply to his attempt at producing a revised German version of the Brown Book. This shows that the coded remark was probably written two and a half years later than MS 115: this latter part of the volume was begun on 14 December 1933, and there is no reason to suppose that it took Wittgenstein more than a few months to complete the rest of his work. So, probably MS $115_{\mathrm{i}}$ was completed before or in the spring of 1934. The German revision of the Brown Book, on the other hand, is dated "Ende August 1936". The last remark of this revision is followed by the well-known words:

Dieser ganze >Versuch einer Umarbeitung von Seite 118 bis hierher ist nichts wert.

That is, Wittgenstein regarded his attempted translation-cumrevision as completely worthless. It is probable that, after giving up work on MS $115_{\text {ii, }}$, it took him a while to get started on the earliest version (Urfassung) of what we know as Philosophical Investigations in November (MS 142). So we may suppose that he worked on this second part of MS 115 from August to September or October 1936.

The first 117 pages of volume XI (often referred to as MS 115, i.e. the first part of MS 115) constitute a continuation of the work 
contained in MS 114ii, and hence a continuation of work on a revision of TS 213 (plus manuscript corrections). Some of it is meant to be inserted into MS $114_{\mathrm{ii}}$; a great part of the first 35 pages or so is based on MS 146 ("C2"), a number of later remarks on MSS 147 ("C3") and 157a; and many of the remarks to be found in MS $115 \mathrm{i}$ were at a much later stage (ca. 1945) copied into TS 228, some of them ending up in publications like Philosophical Investigations or Zettel.

Parts of pp. 95 and 100 as well as the whole of pp. 96-99 consist of typed material from an (almost clean) copy of TS 213, pp. 393398 (=211, pp. 604-609). These remarks are chiefly on the principle of induction and related topics, cf. the 470s and 480s of PI.

The second and somewhat larger section of MS 115 (=115 $5_{\text {ii }}$ continues Wittgenstein's pagination (118-292). The underlined title (Philosophische Untersuchungen) was squeezed into the space between the first line ("Versuch einer Umarbeitung") and the page number; it is hence likely to have been added at a later stage. The date ("Ende August 36") is squeezed in even more tightly than the title, so there is a certain probability that it too was added at a later time.

There is an obvious and obviously interesting question about the identity of the English version of the Brown Book that Wittgenstein relied on in translating and revising this text. Some of his modifications are pretty radical; others seem slight but, on closer inspection, turn out to be important clarifications. Serious work on comparing different versions, especially various Ambrose copies of the Brown Book and the Skinner copy of Wittgenstein's dictation, will need to be done in the future. Some of Wittgenstein's additions and corrections in the Skinner copy as well as the emotional value that this particular copy must have had for Wittgenstein speak in favour of accepting the conjecture that it was this latter copy which Wittgenstein took with him to Skjolden and used in the process of producing MS $115_{\text {ii }}$.

The great number and characteristic style of corrections in this manuscript show that Wittgenstein worked directly on the text as contained in this volume, that is, he probably did not rely much on other (smaller and more tentative) notebooks to compose this version of "Philosophische Untersuchungen". 
The contents of MS $115_{\text {ii }}$ are known to readers of the German version of the Brown Book (ed. by Rush Rhees and published under the title Eine philosophische Betrachtung).

\section{MS 116}

\section{Philosophische Bemerkungen}

This manuscript volume is the biggest one in Wittgenstein's whole Nachlass. It is a large ledger containing 347 manuscript pages. The volume is customarily divided into four parts as follows: MS $116_{\mathrm{i}}=$ pp. 1-136, MS $116_{\mathrm{ii}}=$ pp. 136-264, MS 116 $6_{\mathrm{iii}}=$ pp. 265-315, MS $116_{\text {iv }}=$ pp. 316-347. This last part is the only one bearing a date in Wittgenstein's hand: "May 1945". The third part, however, cannot be much older than this, as von Wright recognized on the basis of the specific content of these remarks; he tentatively characterized them as being connected with material written in 1944. The second part, on the other hand, is clearly continuous with part one. While it does not carry on the work on TS 213 (the Big Typescript) commenced in part one, it proceeds in a way similar to the earlier presentation of remarks and is hence not obviously distinguishable from earlier remarks. Most of the material used in the second part originates in MS 120, which is to say that it was first written down between November 1937 and March 1938.

It was only when it became clear to scholars that journal entries of 23 to 26 October 1937 (in MS 119) report on the genesis of MS $116_{i}$ that they came to see why this material is not to be regarded as a continuation of the two Umarbeitungen contained in MSS $114_{\mathrm{ii}}, 115_{\mathrm{i}}$ and 140. In the autumn of 1937, Wittgenstein looked at these writings with completely different eyes from 1933/34. Now he was studying remarks belonging to an earlier period of his thought, and owing to this change of perspective, he could only select but not really develop this older material. In MS 119, 79r ff. Wittgenstein reports:

I started to look at my old typescript and to separate the wheat from the chaff. If only they could be separated more neatly! [...] In examining my old remarks I feel as if I were supposed to restore the household 
goods of a flat by pulling objects out from a rubbish heap and subsequently trying in a fussy way to examine and clean them [...]. Am reading my old remarks. The great majority strikes me as fairly indifferent; a great many of them are feeble. [...] The best ones are those that simply articulate a problem. [...] There is plenty of thought behind these remarks. But only a few of them can without revision be used for a book.

In MS 116 Wittgenstein introduces a way of referring to his remarks which readers need to be aware of in studying relevant manuscripts or typescripts: the individual remarks on each page are numbered 1, $2, \ldots$, and this way of numbering is then applied to the remarks on every fresh page. Thus, "97/3" would refer to the remark numbered " 3 " on p. 97 of MS 116. The fact that the same way of numbering remarks was then applied to MS $116_{\mathrm{ii}}$ — that is, to remarks that do not come from the Big Typescript but mostly from MS 120 suggests that at one point Wittgenstein must have thought that he could make further use of the remarks in both parts for the same purpose or, at any rate, for related purposes.

However this may be, MS $116_{i}$ covers $\iint 1$ to 44 of the BT, that is, a great part of the chapters on Understanding, Meaning, Proposition: Sense of a Proposition, Immediate Understanding and the Application of a Word in Time, and the Nature of Language. Especially towards the end of this part of MS 116, readers will find a number of new remarks that may have been inspired by reading the old remarks from the BT. Here it is important to remember that a substantial selection of remarks from this part found their way into Bemerkungen I and II (= TSS 228 and 230), and hence into PI, since TS 228 was one of Wittgenstein's chief sources in composing the last version of the Investigations.

As we pointed out before, MS 116 ii mainly draws on MS 120. Especially at the beginning, there are a fair number of remarks without known predecessors. A few remarks are derived from MS 158 (begun on 24 February 1938, in Dublin). So it is likely that work on MS $116_{\text {ii }}$ was done during Wittgenstein's stay in Dublin or a little later. A number of the remarks in this part of MS 116 were later selected and transferred to TS 228 and, in some cases, to the last draft of the Investigations. 
MS $116_{\text {iii }}$ is a bit of a miracle: none of the remarks contained in this part seems to have a known antecedent. On the other hand, most of them do not in the least look like first drafts. At any rate, if one judges these remarks by their contents, von Wright must be right in supposing that the bulk of this material was written in or around 1944. Again, a fair number of these remarks were selected and, by way of dictation, transferred to TS 228. From here, some of them found their way into the Investigations.

The fourth part, MS $116_{\text {iv }}$, is the only part bearing a date in Wittgenstein's hand ("May 1945"). As it seems, all or virtually all of these remarks are new in the sense that no antecedents can be found in earlier manuscripts. And again, even though they do contain a few corrections and deletions, they do not really look like remarks belonging to a first draft. A fair number of them were transferred into TS 228, and many of these found their way into PI. Perhaps one will regard it as hard to believe that such a great proportion of remarks that in Wittgenstein's judgement were up to standard had no predecessors in earlier manuscripts. But it may of course be the case that at this point (in the summer of 1945) he knew exactly what he needed in order to fill gaps he perceived in the penultimate version of his work and thus tried hard to write precisely what he required.

(For the complicated story behind our present view of MS 116, see von Wright's account of the matter in "The Wittgenstein Papers" [in: Wittgenstein, 50-52; or in: PO, 494-5] and in "The Origin and Composition of the Philosophical Investigations" [in: Wittgenstein, 122125]. Another part of the story is told in my paper "The Role of the Big Typescript in Wittgenstein's Later Writings", in: Nuno Venturinha [ed.], The Textual Genesis of Wittgenstein's Philosophical Investigations [2013], 81-89.) 


\section{MS 117}

\section{Philosophische Bemerkungen}

As has been pointed out in the General Note, the first part of MS $117\left(=117_{\mathrm{i}}\right)$ serves chiefly as a receptacle for remarks selected from MS 118 and, to a much smaller degree, from MS 119 (the last of these latter kinds of remark was written on 7 October 1937, cf. MS 117: 96, MS 119: 81-83). Many of them were later transferred into a typescript (TS 221) which, in its turn, was the basis for a rearrangement of remarks (TS 222), more or less the same as remarks in Part I of Remarks on the Foundations of Mathematics (3rd edition 1978). There can be little doubt that MS $117_{i}$ was meant to result in the second part, as it were, of the early version of the Investigations. To what extent this material was really intended to constitute a sustained examination of problems in the philosophy of mathematics or, perhaps, of ideas about the foundations of mathematics is a question that needs to be discussed in a different context. At any rate, many of the remarks to be found here are wellknown from RFM or the published version of TS 221 (Kritischgenetische Edition of PU, Frühfassung). A couple of remarks from MS $117_{i}$ ended up in the Investigations $\left(\$ \int 607,608\right)$.

The second part of this manuscript $\left(117_{\text {ii }}\right.$ is fairly short (117: 97$110)$ and seems to stand in no direct relation with any other manuscript. It bears the title "Ansätze" and was published in part II of RFM (\$S1-22, on Cantor's diagonal method, etc.). In view of the fact that MS 117 $\mathrm{i}$ was completed in October 1937 while the beginning of MS $117_{\text {iii }}$ was written on 27 June 1938, we can be sure that MS $117_{\text {ii }}$ was composed sometime between these two dates.

The third part of MS 117 (MS 117 $7_{\mathrm{iii}}=$ MS 117:110-126) is almost as short as MS 117 ii. It bears the date "27.6."[1938] and consists of three drafts of Wittgenstein's preface to what is known as the early version of the Investigations (TS 225, dated August 1938, published in Kritisch-genetische Edition of PU, 207-9). For even earlier drafts, 
see Alois Pichler, Wittgensteins Philosophische Untersuchungen: Zur Textgenese von PU $\iint 1-4$ (Bergen 1997).

The fourth part of MS 117 (MS 117 iv = MS 117: 127-148) seems to continue the work begun in MS 116: it selects and revises remarks taken from TS 213 (= BT). On just over 20 pages Wittgenstein covers 10 sections ( $\$ \int 48$ to 57 ) of the BT, mainly dealing with various aspects of our concept of thought or thinking. Towards the end of this part, the reader encounters independent reflections on the notion of a law, on Gödel, and on the idea of a sentence-radical, etc. - There is some overlap between two or three remarks from the beginning of this part and a short section of MS 121, written between 17.7. and 5.9.[1938]. This fact may help us in trying to assign a date to this material.

The fifth part of MS 117 (MS 117 $=$ = MS 117: 148-273) contains the closing section of the series of Bände commenced in vol. I (= MS 105). Its title is "Continuation of Volume XVIII" [= MS 122]. Its pages are continuously dated from 3.2.40 to 16.6.[40]. The main part runs on to 20 March (p. 270). Then there follow a few scattered remarks, in part belonging to Wittgenstein's journal, jotted down on 27.3., 6.4., 18.4., 7.6., 15.6., and 16.6. Most of the remarks to be found in the main part seem to be similar to RFM-related material or material known from the notes of lectures Wittgenstein gave on questions concerning the foundations of mathematics. (RFM III, \\59-90 was culled from MS 117v.) To mention just one recurrent theme: he keeps returning to his comparison between an anthropological and a purely mathematical description of people's calculations. - Most of the material written on 22 February is more or less the same as remarks found on pp. $25 \mathrm{r}$ to $28 \mathrm{r}$ of MS $162 \mathrm{~b}$. This section contains one instance of Wittgenstein's famous observation to the effect that a proof creates a new concept. There are a few remarks belonging to Wittgenstein's journal as well as observations of a more general nature of the kind collected in Culture and Value. 


\section{MS 118}

\section{Philosophische Bemerkungen}

This manuscript volume was begun while Wittgenstein was travelling to Norway. The first entry was written on 13 August 1937 (in a place called Mjömna). On 17.8. he says that he has arrived in Skjolden, where he spends the first days, not in his cabin, but with friends. The first pages of this manuscript are devoted to recording impressions and feelings, fears and hopes. He does, however, soon move on to writing philosophical notes, mostly belonging to what we are used to call the philosophy of mathematics or foundational studies. These notes, however, are frequently interspersed with journal entries of a personal nature and sometimes of a general kind. Most remarks of the latter type have been published in Culture and Value.

A fair number of Wittgenstein's philosophical remarks were selected, revised and transferred to MS 117: evidently, in working on this material he used both manuscript volumes (XIII and XIV) at the same time. And there is a short period (towards the end of MS 117i) during which he even used three volumes (XIII, XIV, and XV) contemporaneously. On p. $95 \mathrm{r}-\mathrm{v}$ (16.9.) we find one of the earliest drafts of part of the preface to the early version of PI. The last entry of MS 118 was written on 24 September 1937, and on the same day, Wittgenstein wrote the first remarks of MS 119, continuing his reflections on themes familiar to readers of Part I of RFM by material edited and published by Rush Rhees under the title »Cause and Effect: Intuitive Awareness«. Thus, it took Wittgenstein less than seven weeks to fill the whole of volume XIV as well as ca. 90 pages of MS 117.

\section{MS 119}

\section{$X V$.}

As was pointed out before, this manuscript volume forms the immediate continuation of volume XIV. The latter was completed on 24 September 1937, and on the same day, Wittgenstein entered 
his first remark in MS 119 - a remark which much later became §415 of the Investigations.

In this volume, the pagination given in transcriptions may be a little confusing. Basically, it is Wittgenstein's own page numbers that are assigned up to p. 147 (21 October 1937), but at this point, Wittgenstein discontinues his previous way of allotting a number to every single page. So, from this point onwards, pages are counted according to a system of foliation, starting from p. $74 \mathrm{v}$ (up to $148 \mathrm{r}$, 11 November).

Again, the manuscript volume serves as a kind of journal. It records two visits: Francis Skinner, after spending just over a week in Skjolden, leaves on 30 September, and on 1 October, Wittgenstein gratefully records that the last five days have been »beautiful«. (In MS 118, the journal records that Wittgenstein had left Skjolden on 18 September to meet Skinner in Bergen, and that by 22 September they had arrived in Skjolden.) A second visitor was Hermann Hänsel, the son of Wittgenstein's old friend Ludwig Hänsel, whose presence is recorded on 10 October and who is said to have left on 12 October. In his journal, Wittgenstein states that Hänsel made "a good impression" (cf. letter to Hänsel 12.10.37).

Philosophically speaking, this volume is a veritable treasure house. It includes remarks on the "hardness of the logical must", an important allusion to Tractatus 6.1261 (25.9.), as well as valuable observations on language-games, forms of life, and various aspects of the idea of privacy. Moreover, MS 119 contains the bulk of the material edited and published by Rush Rhees under the title »Cause and Effect: Intuitive Awareness « (see the version published in Philosophical Occasions [1993], pp. 368-426). Half a dozen general remarks have been published in Culture and $V$ alue.

At one point (p. $77 \mathrm{v}$ ) a remark is entitled "Nachtrag aus einem Heft" ("supplementary observation from an exercise book"). This is taken from MS 152: 29. 


\section{MS 120}

\section{XVI.}

This manuscript volume spans the time from 19 November 1937 to 26 April 1938. Thus, it is the immediate continuation of MS 119 (the first page bears the "title" "Fortsetzung des Heftes XV" "Continuation of Volume XV"). Entries are dated throughout.

The journal Wittgenstein kept in previous manuscript volumes is continued. Besides records of his impressions and emotional states, it contains (quasi-)religious reflections and notes on how his work is going. He keeps worrying about the question whether he will be capable of doing decent work during the rest of his stay in Skjolden.

Many of the remarks drafted in MS 120 were then used to fill pp. 161-258 of MS 116 $6_{\text {ii. }}$ A fair portion of this material was later used in dictating TS 228, and a number of these remarks were inserted in the final version of the Investigations. There is a good deal on the language of pain, Äußerungen (avowals), the visual field (there are explicit references to Tractatus 5.633), and the grammar of philosophically important terms like »to know«.

The journal kept in this manuscript volume shows that 10 December was Wittgenstein's last night in Skjolden during this period: on 12 December, he finds himself on the boat to Bergen. Apparently, he uses his long journey to write a number of philosophical as well as personal remarks. The first entry for 19 December states: "In Wien". The journal is kept for another few days, but there is no entry to be found between 6 January and 8 February 1938. On this day, Wittgenstein writes that he has arrived in Dublin. Here, work on his philosophical remarks continues. There are occasional references to visits to the psychiatric ward where Wittgenstein's former pupil Drury was working. In March, he feels that the political situation in Austria increasingly worries him. On 15 March, he writes a long letter to Gilbert Pattison concerning the question of taking British citizenship (see MS 158 and Wittgenstein in Cambridge, no. 218). By 18 March, he has arrived in Cambridge and spoken to Sraffa, who warns him of returning to Vienna and offers help. 
The brevity and jerkiness of most entries following this date until Wittgenstein reached the end of this volume on 26 April show that he was too concerned about his own destiny and that of his relatives to get much concentrated work done. Moreover, as Wittgenstein evidently wished to give classes in the Easter term, he had to organize things and to get in touch with people who could help him to find a teaching position.

For ease of reference, the contents of this volume may be divided into MS 120 (including Wittgenstein's stay in Vienna up to 6.1.38) and MS $120_{\mathrm{ii}}$ (comprising the rest of this volume from 8.2.30 [Dublin]).

\section{MS 121}

\section{Philosophische Bemerkungen}

The first entry in this manuscript volume bears the same date as the last entry in Band XVI (26 April 1938). So it constitutes the immediate continuation of Wittgenstein's previous volume. The last entry is dated 5 January 1939 . So the volume taken as a whole covers a time span of over eight months. There is a clear break, however, in the middle of this manuscript volume: after what appears to be the last remark written on 17 July 1938, Wittgenstein draws a line across the page; the following three remarks bear no date (cf. MS 117 iv), and then another line is drawn. The next remark bears the date 5.9.38 (121: 48v) and introduces a brief discussion of sense-data. The following pages consider all kinds of questions concerning the philosophy of mathematics and contain material later transferred to TS 221. The next date (after 5.9.) is "25.12.38" (121: 60r). So one may want to speak of another gap between (roughly speaking) September and December 1938. The last entries were evidently written on 5 January 1939.

A fair number of remarks written on 25 December and the following days (up to 3.1.39) were selected and published by the editors of RFM as $\$ \$ 40$ to 61 of the second part of this book. $\int \$ 23$ to 39 of this part were taken from an earlier section of MS 121 (dated 
30.5., 10.6., 11.6., 12.6., 13.6., and 12.7.), while $\$ \$ 1-22$ are based on the section entitled »Ansätze« from MS 117 (=117 ii).

In addition to these remarks on the philosophy of mathematics, this manuscript volume contains a number of remarks on the language of pain, on images, and on memory. It is similar to previous volumes in recording Wittgenstein's thought day by day, but it differs from these volumes in containing virtually no personal remarks, i.e. no journal. Moreover, readers will find only a couple of general observations printed in Culture and Value.

Abstracting from the fact that some chronological gaps might be filled by entries in smaller notebooks from the same time, gaps like those between July and September or between September and December 1938 can easily be explained by Wittgenstein's worries and the pressure he was working under in those months. And of course, teaching and various activities connected with applying for the Cambridge chair that would fall vacant after Moore's retirement will also have contributed to his not finding sufficient time and concentration to continue sustained work on his manuscripts.

\section{MS 122}

\section{Philosophische Bemerkungen}

There is an interval of more than ten months between the last entry in MS 121 (5.1.39) and the first entry in MS 122, which bears the date 16.10.39. The entries in this manuscript volume are continuously dated, and there is hardly a day during this period without a remark or several remarks. The last remark was written on 2 February 1940. The last words are "Fortgesetzt in Band XIII" ("Continued in Volume XIII"), and indeed MS 117, forms the immediate continuation of the material in Volume XVIII (see our notes on $117_{\mathrm{v}}$ ).

The pagination, even though not everywhere continuous, is Wittgenstein's.

The vast majority of remarks to be found in this volume belong to the philosophy of mathematics. Selections from this material were published in Part III of RFM (see $\int \$ 1-58$ ). Among the topics 
discussed are our concept of a proof and the idea of a proof picture or figure, the grammar of words like "proof" or "construction", the (im)possibility of drawing a clear boundary line between empirical and logical statements, our notions of a rule of inference in particular and of a rule in general. Wittgenstein goes on to discuss his slogan that a proof can create concepts, and he keeps worrying about the danger of falling into dogmatism. Another question he raises is that of the relevance of grasping possible and actual applications of a calculation to understanding the calculation itself.

This volume contains a few journal entries and a handful of remarks of the general type collected in Culture and Value.

(C) Joachim Schulte and the Wittgenstein Archives at the University of Bergen. 